\title{
Typhus in the Warsaw Ghetto 1940-1942: how an epidemic increased exponentially, was abated and eventually disappeared
}

\author{
Hermann Feldmeier \\ Institute of Microbiology, Infectious Diseases and Immunology, Campus Benjamin Franklin, Charité University Medicine Berlin, \\ Berlin 12203, Germany. \\ Correspondence to: Prof. Hermann Feldmeier, Institute of Microbiology, Infectious Diseases and Immunology, Campus Benjamin \\ Franklin, Charité University Medicine Berlin, Berlin 12203, Germany. E-mail: hermann.feldmeier@charite.de
}

How to cite this article: Feldmeier H. Typhus in the Warsaw Ghetto 1940-1942: how an epidemic increased exponentially, was abated and eventually disappeared. One Health Implement Res 2021;1:51-5. https://dx.doi.org/10.20517/ohir.2021.03

Received: 4 Mar 2021 First Decision: 29 Mar 2021 Revised: 30 Jun 2021 Accepted: 1 Jul 2021 Published: 17 Nov 2021

Academic Editor: Jorg Heukelbach Copy Editor: Yue-Yue Zhang Production Editor: Yue-Yue Zhang

\begin{abstract}
Typhus, a bacterial infection caused by Rickettsia prowazekii, was widespread in Europe for centuries and was endemic in Eastern Europe until the 1950s. Between 1940 and 1942, a devastating typhus epidemic occurred in the Warsaw Ghetto causing an estimated 16,000-22,000 deaths. Between November 1940 and October 1941, the epidemic increased exponentially. After a sharp peak in October, the trend reversed, and the number of new infections decreased to reach zero in July 1942. Until recently, epidemiologists were unable to explain the peculiar shape of the epidemic curve. Based on the memories of Ludwik Hirszfeld, a Polish physician and microbiologist who spent three years in the Ghetto, it seems that improvement of diagnosis, health education and measures targeted at the interruption of the transmission of $R$. prowazekii via body and head lice led to a turnaround of the epidemic's dynamics and eventually to the elimination of $R$. prowazekii. Notably, all measures developed by Hirszfeld were implemented without the knowledge of the German occupiers and functioned in the underground.
\end{abstract}

Keywords: Typhus, R. prowazekii, epidemic, Warsaw Ghetto, body lice, head lice

\section{INTRODUCTION}

Numerous pathogenic microorganisms are profiteers of civil wars and armed confrontations. Not only the 
military conflicts themselves trigger the development of epidemics, but also the living conditions resulting from the chaos associated with war and uproar. Rickettsia prowazekii, the cause of typhus, is a prototype of a bacterial profiteer, when humans are on the run, have to live in crowded conditions in inadequate shelters, no appropriate sanitary infrastructure is available, and malnutrition has a negative impact on immunity. The infectious disease has been well-known since ancient times and was widespread in Europe for centuries (Text box 1). Until the 1950s, typhus was endemic in the rural hinterland of Eastern Europe, and $R$. prowazekii circulated the whole year-round in the population. Since highly effective antibiotics are available, and body lice - the vectors of $R$. prowazekii - can be killed with insecticides, the pathogen has become rare. According to the WHO, typhus still occurs in conditions of overcrowding and poor hygiene, such as in prisons and refugee camps.

Recently, an interdisciplinary group of mathematicians, historians and holocaust specialists has tried to analyze the dynamics of the typhus epidemic in the Warsaw Ghetto during 1940-1942. The epidemic developed in an exponential manner, suddenly came to a halt, then decreased and eventually disappeared ${ }^{[1]}$.

\section{MATERIALS AND METHODS}

The supplementary material provided by Stone et al. ${ }^{[1]}$ was analyzed to better understand the peculiar characteristics of the epidemic. Additional epidemiological and historical data were extracted from the biography of Ludwik Hirszfeld, a Polish physician and researcher who spent three years in the Warsaw Ghetto $^{[2]}$. Hirszfeld himself lived and worked inside the Ghetto from 1939 to 1942.

\section{RESULTS AND DISCUSSION}

After the bombardment of Warsaw in the late summer of 1939, the situation of the inhabitants of the largest city in Poland deteriorated rapidly. Water pipes and sewers were destroyed by bombs. Consequently, the drinking water was contaminated with sewage and toilets did not work properly. With the threat of the death penalty, the German occupiers ordered that all Jews had to move into a ward of the city called the "Jewish Residential District", an area of $3.4 \mathrm{~km}^{2}$. At the same time, thousands of Jewish refugees from the rural parts of Poland moved into this district, which later became known under the name "Warsaw Ghetto". On 15 November 1940, the Ghetto was declared as a "restricted infectious disease area" by the German military administration and was fenced off with an $18 \mathrm{~km}$ long and $3 \mathrm{~m}$ high wall. The residents became trapped in a kind of prison from which escape was not possible and which was dominated by $R$. prowazekii.

Within a couple of months, from a handful of cases of typhus probably imported by refugees, a disastrous epidemic developed, at the end of which about 25,000 people had died. First, only single cases occurred, then a dozen per week and finally up to 100 new cases per $24 \mathrm{~h}$. The reproduction factor R temporarily had a value of 2.2; hence, 10 people with $R$. prowazekii infected 22 healthy individuals. The incubation period being 10-14 days, the number of new cases doubled about every two weeks. The epidemic curve showed the characteristic feature of exponential growth and reached its maximum with 3500 typhus cases in October 1941.

Surprisingly, the number of new cases declined in the following month. The epidemic curve shrank almost as fast as it had increased. In July 1942, nine months after the peak, not a single case of typhus was recorded.

"The gate was closed behind us. It seemed as if we moved from a cold room into an overcrowded, stinking prison, where we stopped to be humans". That is how Hirszfeld ${ }^{[2]}$ described his feelings when he entered the Ghetto in 1939. In the hermetically sealed area, 445,000 people lived temporarily, corresponding to 131,000 inhabitants per square kilometer - the highest population density ever recorded. 
The daily food rations allocated by the German occupiers initially were at 200 calories and increased to an average of 784 calories per day in December 1941 (1800 calories are considered as survival minimum). Water was scarce, and the majority of the public bathhouses were closed. In the absence of coal, the wood from buildings destroyed by bombs was used to fire the stoves.

The Jewish people from the rural hinterland of Poland and occupied towns who had tried to escape from the chaos of war often only possessed one pair of underwear and clothes. Those who possessed various items of clothing wore them one above the other, to protect themselves from the biting cold. Under these circumstances, adequate hygiene was impossible. Obviously, body and head lice benefitted from these circumstances. Hirszfeld's biography suggests that the bloodsucking skin parasites were omnipresent ${ }^{[2]}$.

As soon as a case of typhus became known, the whole family was forced into quarantine for two weeks, and, during this time, they had no access to food. Delousing actions were carried out with brute force by the German occupiers and food supplies were destroyed. Thus, whoever developed symptoms of typhus tried to hide the disease under any circumstance. Family members with typhus were hidden in cupboards, attics and even in the lavatories, Hirszfeld wrote in his diary ${ }^{[2]}$. When somebody died from the disease, their body was carried naked from the house and deposited on the streets in the dark. The clothes - probably still populated by lice - were distributed to those in need.

In their study, Stone et al. ${ }^{[1]}$ tried to calculate the actual number of typhus fatalities of the Ghetto residents. To this end, they synchronized the daily number of food ration cards distributed to the Jewish community with the number of deaths and the number of documented cases of typhus. Since death by starvation and death by typhus were considered to be responsible for almost all deaths, and because observations by Hirszfeld indicated that about a fifth of all patients with typhus died, the authors calculated the cumulative number of typhus deaths to range between 80,000 and 110,000. In a second step, all parameters that may influence the dynamics of a typhus epidemic were entered in a stochastic model, including the assumption that, over time, an improved supply with food might have strengthened the immune system. Actually, the shape of the epidemic curve between November 1940 and October 1941, generated by the stochastic model, was pretty similar to the epidemic curve based on the data from the Jewish Council, only that the peak was significantly higher in the model.

In whatever way the scientists fine-tuned the equations of their model, they could not explain why the epidemic curve peaked in October 1941 and why it declined sharply in the following months. The descending shape of the curve could only be explained mathematically if $R_{0}$ was assumed to be at 0.5 between November 1941 and July 1942.

The memoirs of Hirszfeld deliver an explanation of the perplexing picture. Without the German occupiers suspecting it, Hirszfeld and a dozen of other physicians living in the Ghetto had established a kind of "health council", a network of health activities operating in the underground, with the aim to spread general and specific health knowledge and implement preventive measures against typhus. Even a medical faculty was established in which lectures were regularly given. In addition, a clandestine bacteriological laboratory was implemented, where Hirszfeld instructed students to diagnose typhus. Hirszfeld also performed clinical research, e.g., he proved that a vaccine against typhus provided from the International Red Cross was ineffective.

The people in the Ghetto were instructed on how to free clothes from lice, which was, in view of the shortage of hot water and soap and the few functional public bathhouses, a challenge by itself. People were 
urged to keep distance - during the day and at night - to prevent the transmission of body and head lice. Individuals with signs of typhus had to go into self-isolation. The compliance of this measure was checked regularly.

The health council insisted that strict infection protection measures had to be maintained until no more cases of typhus occurred. Since Hirszfeld was unable to determine the critical limit at which the likelihood of transmission of $R$. prowazekii would tend to come down to zero, a point of time at which control measures could be abandoned was not promised at all. Retrospectively, one can only guess the degree of discipline and solidarity asked from the inhabitants of the Ghetto in order to maintain the rigid protection measures intertwined in the daily struggle for survival in the Ghetto for almost a year.

A comparison of the dynamic of the typhus epidemic in the Warsaw Ghetto to the first 12 months of the coronavirus pandemic is tempting, but only of limited informational value. Without any doubt, the political determinants of the typhus epidemic were totally different from those of the coronavirus pandemic, and the epidemiological context in which the transmission of $R$. prowazekii occurred in the Ghetto was significantly more difficult to tackle compared to the coronavirus pandemic. Besides, there was only a rudimentary medical infrastructure. In the Ghetto, Hirszfeld only had a small hospital at his disposal, in which the bare essentials were lacking. He requested one thousand more beds from the military administration and did not get a single one.

Typhus could not be diagnosed reliably and no effective treatment existed. Insecticides against lice were not available. The lack of clothes and hot water made infection prevention extremely difficult. The chronic malnutrition most likely had weakened the immune system of many people, which probably explained the high fatality rate of about $20 \%$. It is even more astonishing that the dynamics of the typhus epidemic was not only interrupted, but also that zero transmission was reached in July 1942.

Two factors were probably crucial in abating the epidemic: medical knowledge was communicated such that everyone understood it and the clandestine health network ensured that the information got to the furthest corners of the Ghetto. The instructions and recommendations of the physicians were never questioned and the preventive measures - as restrictive as they were - were accepted by everyone. The experience in the Warsaw Ghetto shows that, even under extremely unfavorable conditions, it is possible to control a devastating epidemic.

Presumably, many inhabitants already anticipated that the containment of the epidemic extended their lives for only a short time. The Nazi regime gradually deported all inhabitants of the Ghetto to concentration camps, from which hardly anyone returned alive. Inside the extermination machinery of the occupiers, the knowledge of the heroic efforts of Hirszfeld and his team against the typhus was lost.

\section{Text box 1}

Rickettsia prowazekii - profile of a bacterial profiteer

Bacteria of the genus Rickettsia reproduce only intra-cellularly. Rickettsia is transmitted almost with exception by arthropods. Many blood-sucking ticks, mites, fleas, and lice serve as a vector for the pathogen, in which they can reproduce and through which they are transmitted to the human host by blood-sucking or via feces. The bacterium was named in honor of the American pathologist Howard Taylor Ricketts (1871-1910), who was the first to identify the cause of the Rocky Mountain spotted fever. In 1909, during a study on typhus, he was infected with $R$. prowazekii in Mexico and died two weeks later. The AustrianCzech bacteriologist Stanislaus von Prowazek (1875-1915) was the first to identify Rickettsia in the intestines 
of body lice and therewith proved Pediculus humanus humanus to be a vector of Rickettsia prowazekii. He also died of typhus during research work.

R. prowazekii is transmitted through body lice and probably also through head lice, although unambiguous evidence is lacking ${ }^{[3]}$. Head lice can be infected with these bacteria and Rickettsia can be found in their feces. However, an epidemic of typhus with only head lice as vectors of $R$. prowazekii has never been reported. The pathogen profits from living conditions, in which head and body lice are spread, such as siege, captivity, and exodus. In the past, wars were repeatedly decided by typhus epidemics-and not through weapons. For example, in 1528, the French army lost 30,000 soldiers during the siege of Naples and had to give up its siege. In the Thirty Years' War, the Swedish King Gustav Adolf lost, during the siege of Nuremberg, 18,000 soldiers through typhus within a few months and left the town in peace. In 1944, during the chaos of World War II, the Yugoslavian army had to stop its offensive against the German occupation because too many soldiers were sickened and died of typhus ${ }^{[4]}$.

\section{CONCLUSION}

There is circumstantial evidence that improvement of diagnosis, health education and measures targeted at the interruption of the transmission of $R$. prowazekii via body and head lice led to a turnaround of the epidemic's dynamics and eventually to the elimination of $R$. prowazekii in the Ghetto. Notably, all measures developed and implemented by Hirszfeld and his team were done without the knowledge of the German occupiers and carried out in the underground.

\section{DECLARATIONS}

\section{Authors' contributions}

The author contributed solely to the article.

\section{Availability of data and materials}

Not applicable.

\section{Financial support and sponsorship}

None.

\section{Conflict of interest}

The author declared that there are no conflicts of interest.

\section{Ethical approval and consent to participate}

Not applicable.

\section{Consent for publication}

Not applicable.

\section{Copyright}

(c) The Author(s) 2021.

\section{REFERENCES}

1. Stone L, He D, Lehnstaedt S, Artzy-Randrup Y. Extraordinary curtailment of massive typhus epidemic in the Warsaw Ghetto. Sci Adv 2020;6:eabc0927. DOI PubMed PMC

2. Hirszfeld L. Geschichte eines Lebens. Autobiograhpy. Paderborn, Germany: Ferdinand Schöningh Publisher; 2018.

3. Fournier PE, Ndihokubwayo JB, Guidran J, Kelly PJ, Raoult D. Human pathogens in body and head lice. Emerg Infect Dis 2002;8:1515-8. DOI PubMed PMC

4. Winkle S. Geißeln der Menschheit: Kulturgeschichte der Seuchen. Düsseldorf, Germany: Artemis \& Winkler; 1977. p. 618-63. 